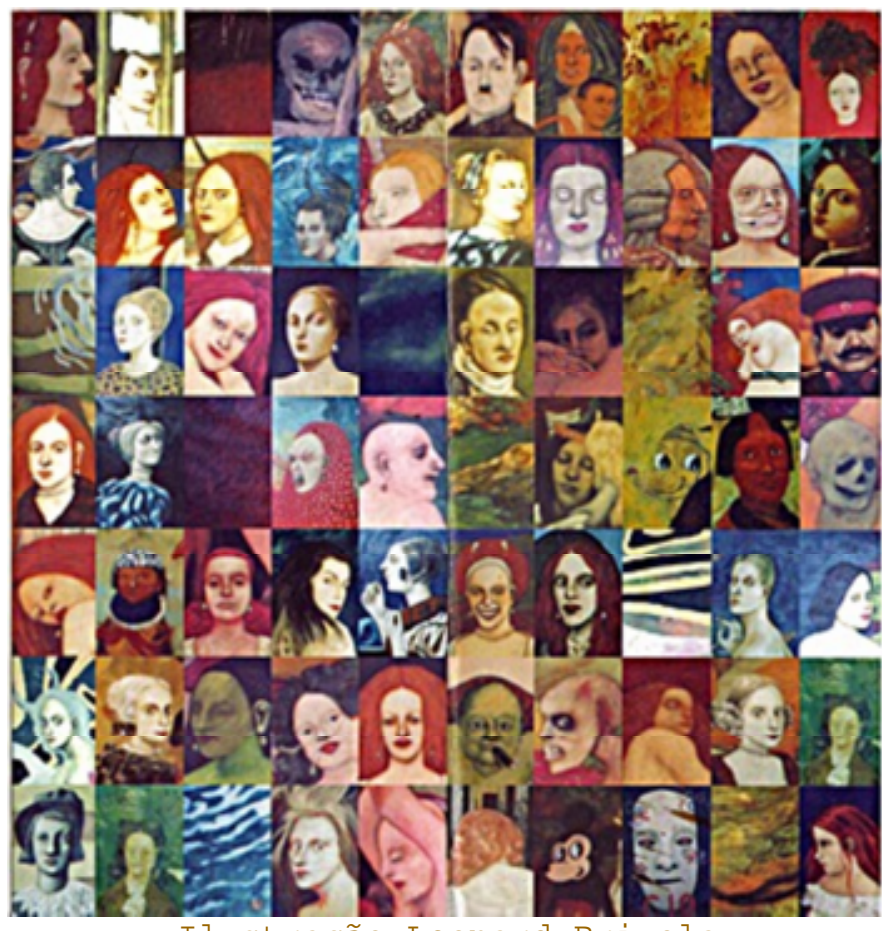

\title{
Prolegômeno \\ a um prefácio interessantíssimo (1)
}

\section{Luiz Fernando Ferreira Sá}

Luiz Fernando Ferreira Sá é doutor em Literatura Comparada pela faculdade de Letras da UFMG, professor de Literatura de Expressão Inglesa na Faculdade de Letras - UFMG e membro do Programa A tela e o texto.

\section{Resumo}

Este trabalho analisa duas exposições do artista plástico mineiro Leonard Brizola. Passando por Mário de Andrade, Lezama Lima e Haroldo de Campos, uma rede textual é estabelecida para dar conta da produção plástica do artista.

Palavras-chave: barroco, pós-modernismo, artes plásticas. 


\section{Orange is human Pink is for dinks}

Imagine - as falas que mais têm significado são aquelas cujo sentido as pessoas não entendem bem.

Imagine - ir a um recital de árias clássicas e durante a execução de uma delas, ainda cantando, a diva entra na coxia para um tour de force backstage e sua voz metálica, perseverante na distância, ressoa em direção a um público atormentado e arrebatado: isto é presença - presença como que no afastamento de um deus.

Imagine - num jogo, o toque de um jogador é de tal forma sutil, que a bola ou peteca cai rente à rede do outro lado do campo (dinks).

Imagine - os trabalhos de Leonard Brizola são preciosos por mais de uma razão; um momento é tudo que se precisa.

"Prefácio Interessantíssimo", como chamo duas exposições de Leonard Brizola, abre-se com assunto vigoroso, para comentar diversas anunciações. Por volta do noivado de Maria e José, Maria, a mãe de Jesus, achou-se grávida do Espírito Santo. José inicialmente decidiu repudiá-la em segredo, mas foi convencido do contrário em sonho por um Anjo do Senhor. Tudo isso anteriormente já havia sido dito, foi uma visão profética: "Eis que a virgem conceberá e dará à luz um filho / e o chamarão com $\circ$ nome de Emanuel / 0 que traduzido significa: "Deus está conosco"(2). Tal é a premissa inicial do primeiro dos conjuntos pictórico-narrativos que faz parte de duas das exposições do artista. No que diz respeito à Virgem e à Anunciação, essa visão acabaria se difundindo nas telas selecionadas para o "Prefácio Interessantíssimo".

Foi também uma visão astrológica, porque logo depois Maria e José iriam conhecer Aquele que nos amou até a morte e que lhes inspirariam as cenas familiares mais belas desse primeiro périplo da vida. Certamente não foi a única paixão desses personagens, mas foi a mais profunda, a mais animadora. Chamou-se Jesus o filho de Maria, que morreu na cruz para salvar a humanidade. Na época poucos acreditaram na sua Ressurreição e na posterior Redenção da vida humana. Com o tempo, essa cena familiar se encheu de significado e passou a ocupar o lugar de origem da vida, ao lado do Gênesis e de tantas outras encenações da origem.

Muitos foram e são os artistas que se encantam com as cenas que narram uma possível origem da vida. Ela era o que dizia a Anunciação, e não lhes faltavam nem lhes faltam as virtudes 
dos comentários e exegeses, que de muito praticados, se tornariam prefácios de prefácios de Prefácios Interessantíssimos. Entretanto - eis a questão -, depois da Anunciação da vida, depois da Redenção da vida e de tantas outras encenações dessa origem, para a re-encenação da vida e de sua origem a simples troca de atmosfera ou ambiente não é suficiente. Usando Mário de Andrade numa citação às avessas, teríamos: "Pintar a origem não significa jamais para mim representar a vida atual no que tem de exterior: automóveis, cinema, asfalto. Se estas imagens freqüentam-me a tela não é porque pense com elas pintar a origem, mas porque sendo minha tela a origem, elas têm nela sua razão de ser". Percorrendo as exposições, vemos que a razão de ser das imagens de vida, no que elas têm de exterior, e nas telas de Leonard Brizola, são menos automobilísticas e mais montanhosamente logísticas, menos cinematográficas e mais imageticamente grafadas, menos asfalto e mais água, aquários e seres aquosos. Esse aguaçal é dos momentos mais belos do "Prefácio interessantíssimo". É também dos mais persuasivos, para aquilo que Leonard Brizola quer mostrar, a saber, que, a partir daquela meteorese (3), 0 trabalho da anunciação se agiganta, tanta força nele pôde despertar o olhar de uma mulher (ruiva, morena, loura )!

Não sabemos o que a Virgem sentiu ao ser "anunciada" ou o que Leonard Brizola sente dessa(s) anunciação(ões). Mas podemos contemplar os resultados. O artista, a partir daí, abre-se para o aguaçal/lamaçal, para a absorção barroquizante de tradições e culturas muito férteis, porém muito conflitantes, como uma Piedade/Santana Afro-Ameríndia que comporta um "Menino Jesus" Indo-Africano aposta a uma Dama Euro-Americana que zombeteia/zumbaia a um Mickey Mouse faceiro e ardiloso. O "Prefácio interessantíssimo" passa a ser percorrido por toda uma aposição quase aporética e fascinante, que Leonard Brizola, muito justamente, entende como o resultado de uma ampla amostragem de atos anunciatórios, de prenúncios, do sabor de prefação, desencadeados a partir de uma estranha experiência pessoal.

Leonard Brizola, entretanto, focaliza as conseqüências pictóricas mais do que as razões idílicas. Pois essas são patentes, e aquelas estão sob o efeito de um claro-escuro que não sabemos bem o sentido, mas que apontam para uma transformação sem precedentes, que não apenas transformação da vida em imago vitae, mas transformação da vida em vida. Essa me parece, até agora, a formulação mais abrangente que Leonard Brizola faz do tema da Anunciação. As exposições são longas e têm um ritmo de uma epopéia barroca. Compõem-se de uma polaridade, a Anunciação e o barroco. 0 andamento das narrativas pictóricas admite desdobramentos. Não obstante, nós queremos sentir tantas presenças. E elas se retiram em reticências. O que é anunciado (não só na Anunciação, mas 
também nas diversas visadas estranhadas dos personagens de Leonard Brizola)? Como ler as telas, o texto que elas compõem e o mundo no qual estão inseridos? Qual é o sentido do "Prefácio interessantíssimo"? A coletânea de anunciações e visadas estranhadas poderia ser um cisma entre o pósmodernismo das anunciações desviadas e as promessas barrocas de estranheza, ou poderia ser o resultado de uma busca de pintura "barroquizada" em pleno pós-modernismo? E finalmente: qual é a eficácia das visadas anunciantes?

Um prefácio, mesmo que interessantíssimo, só faz introdução ou advertência a algo que o artista já sabe de antemão, e o que parece profecia pode ser sintoma, e sintoma subjetivo, coisa que, em termos clássicos, responde sempre a um intumescimento de regras. Possivelmente o que é anunciado já é sabido. E o "Prefácio interessantíssimo" aponta a direção do sentido, este vetor em busca de um acidente. A prova é que o artista retrabalha a visada à distância e ao anverso, tanto antes como depois de saber do já sabido. É como se apenas o momento, o mo(vi)mento de uma anterioridade, de um antes, contasse nesse prefácio. Pois não houve recrudescência das visadas ou do já sabido, ao contrário do que houve no barroco como movimento na historiografia da arte. Houve, quando muito, a clássica sublimação, por meio da pintura. Desta é que Leonard Brizola não se pôde separar. Em seus resultados, este foi um caso um pouco semelhante ao cansaço clássico de Lezama Lima: "É a forma em devir em que uma paisagem vai em direção a um sentido, uma interpretação ou uma simples hermenêutica, para ir depois em busca da sua reconstrução, que é o que marca definitivamente sua eficácia ou desuso, sua força ordenadora ou seu apagado eco, que é a sua visão histórica" e mais, a eficácia dessas visadas anunciantes nesse "Prefácio Interessantissimo" tem, como num "[b]om signo americano, a fineza de solicitar com mistério, como nesse marcante antecedente, como num sonho que a fina atenção alheia vê-se obrigada a decifrar" (4).

As visadas anunciantes e o "Prefácio interessantíssimo" devem ter sido belos acasos. Pois não é qualquer acaso que solicita, nesse "marcante antecedente", uma atenção, uma interpretação ou simples hermenêutica. É preciso uma certa conjunção astral. Algo do momento de atenção ou apreciação deve gloriosamente confirmar esse fato antecedente, fazer a síntese, mesmo que já e sempre procrastinada, entre o espírito e os eventos. Tudo se passa entre Leonard Brizola e suas ruivas figuras de visadas anunciantes, e entre as últimas e os "caprichos" dos olhares atentos. Teria vindo daí o impulso para essa visão astrohistórica? Teria sido em função de uma força ordenadora ou de seu apagado eco que o artista passou a produzir um novo mundo (cheio de meninos índios e sacis-pêrêrê), uma nova aquacosmese? Ou seja, a origo vitae n’água. Ou teria sido o 
contrário? O "Prefácio interessantíssimo" fora um signo que a origo vitae "tá n'água"?

Um signo dessa natureza estranhada nas telas do artista, um sinal. Esses signos fazem com que nunca mais sejamos os mesmos. Não obstante, as visadas anunciantes foram absorvidas pelo olhar do espectador, uma leitura. O cosmos aquoso de Leonard Brizola e sua anunciação são descontrolados. Isso, enfim, é barroquismo. O ego, "interesse" astrológico, se debate com a liberdade infinita que os astros oferecem. Rendeu-se o "Prefácio interessantíssimo" ao sujeito solicitante, ao sujeito decifrante e leitor.

E é por tudo isso que Leonard Brizola aí expressa, num imago vitae disseminado, visadas estranhantes e estranhadas em meio a montanhas, corredeiras d'água, e astros alucinantes e em termos de avatar e profusão prefaciais. Pois essas são as visadas que o mundo contemporâneo permite. A natureza não é mais uma bela senhora, e menos ainda uma senhora de bom senso. A natureza, portanto, sobra solitária aquém do "Prefácio interessantíssimo". E, se não fosse assim, ela só poderia ser simulacro, o único que poderia contar, em vez de novos topoi, nova história. Leonard Brizola, portanto, não representaria a natureza de fato, ou o que dá no mesmo, teria traduzido, num contexto barroquizante, o "novo" topos pós-modernista (o signo do signo) inaugurado na modernidade.

Esse "signo do signo" é ainda a herança mais atual do antiidealismo lírico moderno. O que não nega que o artista o tenha experimentado "entericamente", como os resultados pictóricos bem o mostram. Mas, me parece, Leonard Brizola não sofreu do corpo ou da existência tanto como sofre dos signos, ou seja, da profusão de mônadas, de avatares de representação, que perfazem uma rede de poéticas da modernidade, em sua busca de afinidades químicas, busca de uma nova re-presentação. Por isso é que Leonard Brizola, nesse caso, bem entendido, rasura - signo, a representação pictórica, no mo(vi)mento de reinterpretação e mudança, e que, no limite, também define as artes plásticas como re-presentação contínua.

A dúvida é se houve nos trabalhos apresentados por Leonard Brizola uma transformação da natureza ou uma nova intuição da (ir-)realidade dos signos eficazmente computável no seu universo de imagens. O mais seguro, porém, é que o artista trabalha com a "química" dos gêneros pictóricos, barrocos ou pós-modernos. O que, por sinal, sugere preciosismo no caso de Leonard Brizola. O barroco, quando não foi abandonado, acabou fomentando as correntes contra-reformistas no pensamento pósmoderno e pós-colonial. Ele é anti-convencional e isso lhe dá uma liberdade re-presentacional que, no limite, o aproxima da audácia das origens. Sem a História, sem a dialética do senhor 
e do escravo, ou sem a dialética da matéria. As representações ora resenhadas são barrocas no tema, são pósmodernas nas linhas que delimitam o signo transformando-o em simulacro e são pós-coloniais na digestão (al)química de tradições européias (figuração, narrativa, intertextualidade).

Leonard Brizola pôde, na coletânea das obras que fazem parte das duas exposições, expor ricamente sua linguagem desabusada e inventiva que, há mais de 15 anos empolga sua fatura de imagens, personagens e seres estranhos. Esse é um momento em que o artista se entrega à discussão das artes plásticas como um fato físico, semiótico e social. Haverá, portanto, uma confluência entre uma fazer radical (na tela) e uma expectação de princípio (o olhar do espectador e sua leitura). Há, nessas exposições, uma necessidade de transitar por entre fronteiras, ora enfatizando uma estranheza radical (como na sua monumental portada do inferno), ora enfocando cenas bucólico-fáusticas, cuja estranheza é apenas entrevista.

Aí até vai sua cautela contra as confusões, mesmo que numa grandiosa profusão. E é aí mesmo que se define seu "realismo", um pouco na linha do jovem Bosch, para quem a realidade vinha a ser a síntese entre os efeitos físicos e as relações com o estranho, com o demoníaco, ou com a materialidade da consciência (também religiosa). Daí a materialidade da sua linguagem pictórica, e mais alguns pontos que não destoam da revivescência barroca: a materialidade da consciência; a vida como ação, encenação, jogo e transformação; a consciência como constituição sígnica, até mesmo simulacral; a revolução ou contraposição formal e genérica; e, sobretudo, a dimensão da materialidade como um non plus ultra da existência, a teatralidade do ser. Não são pontos anti-religiosos. São pontos formais.

Ora, esse esforço da forma talvez seja resultado da contínua luta contra a representação e a favor da re-presentação. A figuração na obra de Leonard Brizola é contra a figuração. Isso de um lado. Do outro lado, a condição material de sua linguagem só poderia dar a esta uma $f(r)$ atura própria, tal como acontece com as coisas, que, por serem coisas, abrem um campo e iniciam um jogo de objetivação particular e personalizado. Atento à "revolucionária" produção artística atual, na era da pós-modernidade, Leonard Brizola parece entender sua linguagem pictórica como coisa (das Das), e coisa material. Ou seja, sua figuração e tratamento pictórico de base, pedem suor, trabalho, e tudo isso se vincula a uma intervenção na "realidade" das coisas e nas coisas da cultura. Indiretamente, isto confinaria com o barroco e com o pósmoderno, na insistência de ambos que a linguagem (palavras, imagens, signos) são coisas e coisas em processo de transformação. 
Vimos que foi como coisa que Leonard Brizola usurpou a Anunciação em um "Prefácio interessantíssimo", para efeito de seu barroquismo, e que o fez balizando sua $f(r)$ atura numa disseminação, numa multiplicidade. Uma coisa tem um fim. É constituída para ter um fim. A Anunciação, não. As anunciações prefaciais ou as visadas estranhadas frente a tais anunciações podem ser vitais: imago vitae. Mas não têm partido: origo vitae aracnídeo e em rede (ver, por exemplo, a tela Aracne). Essas anunciações/visadas são a própria descontração de engendrar formas novas, não através de um cogito que delimite, mas através da interação com a vida. Uma interação que não mostra finalidades, mas que são coisas e relações.

Enfim, a coisificação das formas de uma linguagem, como no trabalho de Leonard Brizola, indica que a materialidade dos signos não estaria em sua fisicalidade, mas no ato de transformar o destino sem determinar linearmente a trajetória do destino. Trata-se de um jogo. Trata-se de jogadas em dinks: entre uma coisa e outra lança-se o mo(vi)mento da criatividade, a incerta epopéia barroca de vida. Para tanto, é preciso que a figura, com suas visadas estranhadas, tome conta dos olhos, invada o corpo, a alma, desestabilize a vida. Esse fenômeno, essa experiência fenomênica da consciência já é um valor de mercado. Qual é o valor das obras que compõem o "Prefácio interessantíssimo"? Imagine uma sessão de análise (Lacaniana ou Freudiana) na qual o analisando paga ao analista um valor que simbolize uma mais-valia de consciência. Essa experiência analítica é análoga à apreciação do "Prefácio interessantíssimo": a valoração das obras é uma escolha, também como no caso do consultório, com ou sem regresso.

De novo, nossa vida é um sistema que alguns artistas, aqueles que vemos/lemos, podem completar. Naturalmente não assimilamos ou digerimos tudo o que vemos/lemos, mas o sistema tem sua própria maneira de se auto-completar. No caso do "Prefácio interessantíssimo" de Leonard Brizola, o sistema se completa, não na maneira do barroco espanhol - la vida es sueño --, nem na maneira do barroco lusitano - a vida é jogo ou encenação mas num barroco sem clímax, num barroco do pós-utópico do nãoser des-humano. As visadas estranhadas prefaciam ora uma topologia da coisa, ora uma superfície deslocada, ora uma penetração na Origo Vitae de Haroldo de Campos, que por sua vez já é uma penetração no quadro de Courbet, um enquadramento ginecológico: 


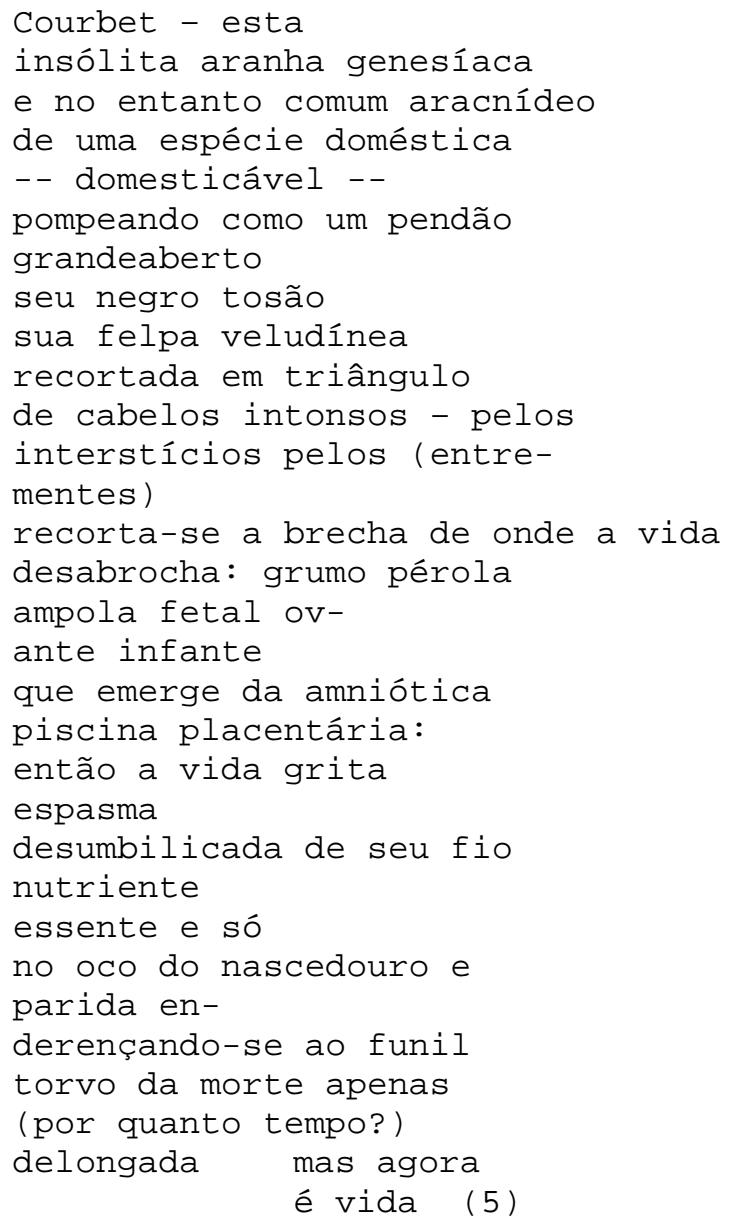

Esse é o falo americano de Leonard Brizola: um barroco aracnídeo-tentacular que penetra courbet, um barroco genesíaco-anular que viola Vermeer. Eis aí mais uma prova decisiva, quando um esforçado da forma, como Leonard Brizola, recebe um estilo de grande tradição (e uma tradição repleta de encenações bíblicas), longe de diminuílo o devolve ainda mais cheio de possibilidades. É vida buscando gozo.

\section{Abstract}

Abstract: This work analyses two exhibits of the plastic artist Leonard Brizola, who works and lives in Minas Gerais. By making reference to Mário de Andrade, Lezama Lima and Haroldo de Campos, a textual net is established in order to read the plastic production of the artist.

Key-words: baroque, post-modernism, plastic art.

\section{Notas}

(1) "Prefácio Interessantíssimo" é o nome por mim dado às seguintes exposições do artista mineiro Leonard Brizola: Exposição Individual Leonard 
Brizola, Palácio das Artes, Belo Horizonte, 2002; e Leo Brizola: Grandes Formatos, Museu de Arte Moderna, Rio de Janeiro, 2005.

(2) Evangelho Segundo Mateus 1:23.

(3) Entendo meteorese como uma criação de mundos/imagens a partir de fenômenos atmosféricos, de estrelas cadentes.

(4) LIMA, 1988, p. 47, 114

(5) Esse poema de Haroldo de Campos, intitulado "Origo Vitae", foi publicado na Folha de São Paulo, Caderno Mais, 1997 e prossegue: "é vida / buscando o seu viveiro / ao arenoso ritmo / fluente e / neutro da ampulheta / que escoa / e depois de gerar / ei-la vaginada aranha / canibal / devolta ao seu mister de / vênus / ao seu monte de pelúcia / alfombra e clitorídea ninfa / e ao seu ofício / carni- / vorante / crua e nua / brasonada / de riçados cabelos / boosco deleitoso / orto meio-aberto meio-ocluso / entre lisas coxas branco-bi- / furcadas-ora / escumoso / bucentauro de núpcias / ora / carenada caverna ou / sorvedouro válvulo / que - / dionéia de cílios / licorosos / drósera orvalhada / e purpurante / ros solis - / devora a carne humana / e lancinada / goza".

\section{Bibliografia}

ANDRADE, Mário de. Poesias Completas. São Paulo: Círculo do Livro, [s.d.]. CAMPOS, Haroldo de. "Origo Vitae". Folha de São Paulo, Caderno Mais, n. 5, 17 /agosto/1997, p. 11 .

LIMA, Lezama. A Expressão Americana. São Paulo: Brasiliense, 1988. 